\title{
PFAPA syndrome: a review on treatment and outcome
}

\author{
Federica Vanoni ${ }^{1 *}$ (D), Katerina Theodoropoulou ${ }^{2}$ and Michaël Hofer ${ }^{3}$
}

\begin{abstract}
The syndrome of periodic fever, aphthous stomatitis, pharyngitis and cervical adenitis (PFAPA syndrome) is the most common cause of periodic fever in childhood. The current pharmacological treatment includes corticosteroids, which usually are efficacious in the management of fever episodes, colchicine, for the prophylaxis of febrile episodes, and other medication for which efficacy has not been proven so far. Tonsillectomy is an option for selected patients. Usually PFAPA syndrome resolves during adolescence, but there is increasing evidence that this condition may persist into adulthood.
\end{abstract}

Keywords: PFAPA treatment, PFAPA outcome, Tonsillectomy, Glucocorticoids, Colchicine

\section{Background}

The syndrome of periodic fever, aphthous stomatitis, pharyngitis and cervical adenitis (PFAPA syndrome) is the most common cause of periodic fever in childhood and it was first described in1987 by Marshall et al. [1]. It is characterized by episodes of fever lasting for 3-6 days with recurrence every 3-8 weeks, associated with at least one of three main symptoms: aphthous stomatitis, cervical adenitis, and pharyngitis [2]. Disease onset is usually before the age of 5 and generally resolves by adolescence. Patients are asymptomatic between episodes and show normal growth. Proposed contributors to pathogenesis include infection, abnormal host immune responses, or a combination of both [3, 4]. PFAPA syndrome is an immune mediated disease characterised by a cytokine dysfunction $[3,5]$; moreover, the strong familial clustering suggest a potential genetic origin of the syndrome $[6,7]$. The presence of variants in inflammasome related genes, mostly in NLRP3 and MEFV, suggest a possible role of these genes in PFAPA pathogenesis [7-9]. However, none of these variants alone seem to be relevant for the disease etiology, suggesting an oligenic or polygenic background.

Currently the diagnosis of PFAPA is based on clinical criteria [2] (Table 1), but these criteria have not been validated in a cohort of patients. Moreover, Gattorno

\footnotetext{
* Correspondence: federica.vanoni@eoc.ch

${ }^{1}$ Pediatric Department of Southern Switzerland, Ospedale Regionale di Bellinzona e Valli, Bellinzona 6500, Switzerland

Full list of author information is available at the end of the article
}

et al. found that a significant number of patients with monogenic periodic fevers also meet the diagnostic criteria for PFAPA syndrome [10], highlighting the poor specificity of the current classification criteria. Therefore, patients should be screened clinically or genetically for other known periodic syndromes before assigning the diagnosis of PFAPA.

PFAPA syndrome has favourable natural history. There is no evidence that medical treatment can modify the outcome, but it can be efficacious for treating the episodes (Table 2). Inducing a rapid remission of episodes is important to improve the quality of life for patients and their families. In this paper we review the current treatment strategies for PFAPA and what is known about the outcome of this syndrome.

\section{Symptomatic treatment during flares}

Non-steroidal anti-inflammatory agents and anti-pyretics have shown poor results in resolving symptoms of PFAPA syndrome. Glucocorticoids are highly effective in aborting the attacks, but there are limited data on the effectiveness of any preventive medication in PFAPA.

\section{Rapid resolution of flare: glucocorticoids}

Orally given glucocorticoids relieve symptoms of PFAPA in a dramatic fashion [11-15].

A single dose of prednisone $(1-2 \mathrm{mg} / \mathrm{kg})$ or betamethasone $(0.1-0.2 \mathrm{mg} / \mathrm{kg})$ given at the onset of an episode can dramatically abort fever attacks in a few hours. 
Table 1 Diagnostic criteria used for PFAPA

I. Regularly recurring fevers with an early age of onset ( $<5$ years of age)

II. Constitutional symptoms in the absence of upper respiratory infection with at least 1 of the following clinical signs : a) aphtous stomatitis,

b) cervical lymphadenitis, c) pharyngitis

III. Completely asymptomatic interval between episodes

IV. Normal growth and development

Aphtous stomatitis, however, can take longer to resolve $[2,16]$. If one dose is not effective in inducing resolution of flare, a second dose may be given the following day.

In the largest PFAPA cohort described so far, Hofer et al. found that 147 out of 301 patients were treated with steroids. They observed a rapid resolution of fever episodes after a single dose of steroids in 93/147 patients (63\%), whereas 46 (32\%) showed a partial response and only 8 (5\%) were non-responders [16]. Data from the EUROFEVER registry confirm the widespread use of steroids for disease flare, with 81 out of 92 patients treated at the onset of attacks, and their effectiveness in 73 patients (90\% of those treated) [13]. Wurster et al. described a cohort of 60 patients in which 44 patients were treated with steroids during episodes and the treatment was effective in 37 (84\%) [17].

Tasher et al., in their uncontrolled series, described that a single low dose of prednisone (mean $0.6 \mathrm{mg} / \mathrm{kg}$ per day) was effective to rapidly resolve the fever episode within an average of $10 \mathrm{~h}$ in 51 out of 54 PFAPA patients [18]. The effectiveness of a single low dose of prednisone was confirmed in a preliminary study performed by Yazgan et al., that did not show any statistical significance in efficacy between a dose of $2 \mathrm{mg} / \mathrm{kg} /$ day versus a dose of $0.5 \mathrm{mg} / \mathrm{kg} /$ day respectively in 40 and 46 PFAPA febrile attacks [19].

The usefulness of steroids is limited by the fact that the interval between episodes may be shortened in 25$50 \%$ of cases $[15,20,21]$. Moreover, the administration

Table 2 Pharmacological treatment for PFAPA syndrome

\begin{tabular}{|c|c|c|}
\hline \multicolumn{3}{|c|}{ Treatment of the episodes } \\
\hline & Dose & Remarks \\
\hline Prednisone & $\begin{array}{l}0.5-2 \mathrm{mg} / \mathrm{Kg} \text {, orally the } \\
\text { first day of fever }\end{array}$ & $\begin{array}{l}\text { Possible to repeat on } \\
\text { day } 2 \text { if fever persists }\end{array}$ \\
\hline Betametasone & $\begin{array}{l}0.2 \mathrm{mg} / \mathrm{Kg} \text {, orally the } \\
\text { first day of fever }\end{array}$ & $\begin{array}{l}\text { Possible to repeat on } \\
\text { day } 2 \text { if fever persists }\end{array}$ \\
\hline \multicolumn{3}{|c|}{ Prophylactic Treatment } \\
\hline & Dose & Remarks \\
\hline Colchicine & 0.5-1 mg/daily, orally & $\begin{array}{l}\text { Gastro-intestinal } \\
\text { side effects }\end{array}$ \\
\hline Cimetidine & 20-40/mg/Kg/daily, orally & Poor efficacy \\
\hline Anakinra & $\begin{array}{l}1 \mathrm{mg} / \mathrm{Kg}, \mathrm{sc} \text { the first } \\
\text { and second day of fever }\end{array}$ & Cost-effectiveness \\
\hline
\end{tabular}

of corticosteroids does not prevent future fever attacks. Side effects are rare; the most commonly reported by Tasher et al. is restlessness. Nevertheless, parents of PFAPA patients are often concerned about the possibility of systemic side effects, and this fact may result in poor compliance.

Finally, the steroid response may be useful in distinguishing attacks of PFAPA from familial Mediterranean fever (FMF) or other hereditary periodic fever syndromes (HPF) $[11,12]$ and can be used as an additional criterion for diagnosis [16]. In fact, HPF attack, except for periodic fever associated with Mevalonate Kinase Deficiency (MKD), usually doesn't show a dramatic response to a single dose of steroids like PFAPA.

\section{Reduction of flare frequency: colchicine}

The precise mechanism of action of colchicine in reducing inflammation is unknown. Colchicine binds to tubulin, forming a tubulin-colchicine complex. This complex can change the structure and the function of the cytoskeleton, thereby influencing neutrophil and lymphocyte migration and adhesion [22]. The rationale for the use of colchicine as a prophylactic treatment for PFAPA is based primarily on clinical and laboratory similarities between FMF and PFAPA and the long-term experience with this drug in the treatment of FMF. For these reasons, when colchicine is effective in PFAPA patients, an alternative diagnosis of FMF has to be considered.

In a 6-month open label, randomized, controlled study, Aviel et al. showed a significant increase in intervals between attacks in 8 PFAPA patients on colchicine therapy compared with 10 patients treated only with corticosteroids. Among the 18 treated patients treated, 8 carried FMF mutations; $6 / 8$ in the colchicine group and $2 / 10$ in the steroid group [23].

Padeh et al. described 10 PFAPA patients previously diagnosed as FMF patients; 6 out of 10 were heterozygous for an $M E F V$ gene mutation (M694V), but had clinical features consistent with PFAPA. Colchicine prescribed to these patients had only a partial effect and was discontinued [24].

In an open label study, Tasher et al. investigated the efficacy of colchicine treatment in 9 PFAPA patients with frequent episodes ( $\leq 14$ days interval). Two patients out of nine were compound heterozygotes for multiple $M E F V$ mutations but exhibited typical features of PFAPA. Colchicine treatment significantly increased the interval between the episodes in eight of these patients [25].

Dusser et al. performed a retrospective, multicenter study in which they reviewed 20 PFAPA patients treated with colchicine. Half of the patients were heterozygous for a pathogenic mutation in the $M E F V$ gene. The authors found that nine patients had no more or suffered half as many episodes during colchicine treatment. No 
significant differences in demographic/clinical variables or the rate of $M E F V$ mutation carriage were found between the two groups (responder and non-responder) [26].

Due to the small size of the samples, Aviel and Dusser didn't find variables that could predict responsiveness to colchicine. Because of the good response of FMF to colchicine, PFAPA patients heterozygous for $M E F V$ mutations may respond better to this drug, but differences in the response to colchicine between carriers and noncarriers of the $M E F V$ mutation have not been demonstrated so far.

Colchicine is usually well tolerated. The most common adverse reactions to colchicine are gastrointestinal (approximately $10 \%$ ). This effect may be partially explained by induction or worsening of lactose intolerance by this medication [25], though multiple mechanism may be responsible.

These findings suggest that colchicine may be an effective second line treatment to prevent frequently recurrent fever episodes in PFAPA patients, in particular if prednisone is decreases the interval between episodes.

\section{Other medications}

Cimetidine, a common $\mathrm{H} 2$ antagonist, has immunemodulating properties, inhibiting chemotaxis and T-cell activation. Cimetidine was suggested as an effective prophylactic treatment for PFAPA in 1992 by Feder [27]. Thomas et al. reported a $43 \%$ efficacy of cimetidine in a group of 28 patients according to data based on telephone recall [2]. Wurster et al. found that in their cohort, cimetidine was effective as symptomatic therapy in 6 out of 25 (26\%) patients while in the remaining patients the treatment was ineffective [17]. None of the 92 PFAPA patients from the EUROFEVER registry, and none of the 42 patients from the Norwegian cohort, were treated with cimetidine, underlining the fact that in recent years this treatment is less prescribed [13, 21]. Moreover, there are no randomized controlled trials supporting benefits of cimetidine to date.

IL-1 plays a central role in PFAPA pathogenesis, as demonstrated by Stojanov et al. [3]. In a small cohort of 5 children with PFAPA syndrome a single dose of anakinra, on the second day of fever, dramatically improved both clinical picture and laboratory parameters [5]. Cantarini et al. described a case of a 27-year-old man resistant to conventional therapy (corticosteroids, colchicine, and tonsillectomy) who was treated with subcutaneous injection of anakinra, with a complete resolution of fever attacks [28]. Despite these interesting reports, the use of IL-1 blockers for PFAPA treatment is restricted to selected cases due to the lack of both randomized trials as well as coverage by health care plans.

Vitamin D has recently gained attention as a possible regulator of inflammation due to the finding that low
Vitamin D levels are associated with some inflammatory disorders [29]. In recent years two studies investigated a possible role of vitamin D in PFAPA syndrome. Mahamid et al. found a significant correlation between PFAPA and vitamin D deficiency, demonstrating a significant difference in vitamin D levels between 22 PFAPA patients and 20 control subjects [30]. Stagi et al. confirmed this finding and demonstrated a significant reduction in the number of febrile episodes and a shortening of mean duration of episodes in patients after vitamin D supplementation (400 IU 25-hydroxyvitamin D daily during wintertime) [31]. However, on the basis of these data it is not possible to conclude that vitamin $\mathrm{D}$ is effective in treating or preventing PFAPA syndrome, and prospective studies on large cohorts of patients and randomized clinical trials are needed.

\section{Adenotonsillectomy}

The role of tonsillectomy in PFAPA syndrome remains controversial. In 1989 an initial study reported efficacy of tonsillectomy in 4 PFAPA patients [32]. Afterwards, a large variability in success rate was reported in other studies. In a randomized controlled trial, Renko et al. compared the effectiveness of tonsillectomy versus no intervention in 26 patients diagnosed with PFAPA (14 underwent tonsillectomy and 12 were observed without surgery) [33]. PFAPA syndrome resolved immediately in all 14 patients randomized to tonsillectomy; in contrast, the syndrome resolved spontaneously within 6 months in $6 / 12$ patients who did not receive tonsillectomy. However, in this cohort, $50 \%$ of the tonsillectomy group and $77 \%$ of the control group had recurrent fever as the only cardinal symptom and thereby did not actually fulfil diagnostic criteria for PFAPA.

Garavello et al. performed a prospective randomized controlled trial with 39 PFAPA patients; 19 underwent adenotonsillectomy and 20 were treated with medical therapy [34]. Six months after surgery, resolution of episodes was observed in 12/19 cases (63\%) and at 18 months follow up they observed complete resolution of episodes in this group within 1 year. In contrast to the findings of Renko et al., only 1 patient in the control group showed spontaneous resolution.

A prospective study by Licameli et al. evaluated the long-term efficacy of adeno-tonsillectomy in 102 patients with PFAPA followed for longer than 6 months after surgery (mean 43 months): Ninety-nine experienced complete resolution immediately after surgery and 1 after 6 months. Of the 2 remaining patients, 1 continued having fever episodes, while 1 was further investigated and subsequently diagnosed with MKD [35].

Although other reports exist, a recent Cochrane review [36] points out that only two randomised controlled trials, conducted on small cohorts of patients, 
demonstrate the effectiveness of the tonsillectomy in treating children with PFAPA. Moreover, these studies show some differences in outcome after surgery, probably due to the heterogeneity of the study population, the choice of different diagnostic criteria, the different type of intervention (i.e., tonsillectomy versus adenotonsillectomy), and the different follow up schedule after surgery. It is not proven that to combining adenoidectomy with tonsillectomy can improve the outcome, compared to tonsillectomy alone.

Considering the favourable evolution of PFAPA and the possible post-surgical complications, adenotonsillectomy should be proposed to selected patients, for example when the interval between attacks is very short in which corticosteroid treatment is not appropriate.

\section{Outcome}

PFAPA syndrome is considered a self-limited disease that generally resolves spontaneously before adolescence $[16,17]$. Patients' growth and development are normal and no long-term consequences have been described [2].

Wurster et al. followed a cohort of 59 patients for a period ranging between 12 and 21 years. Fifty patients experienced spontaneous symptom resolution without relapse; only 9 maintained typical cardinal PFAPA symptoms, though fever was less frequent [17]. They also observed a significantly higher frequency of family history of periodic fever in the patients with persistent symptoms in adulthood.

In a Norwegian cohort, thirty-seven children were followed until resolution with a median follow up of 18.7 months (range 7.2- 75.7). The median age at the time of resolution was 52.1 months. Interestingly, eight children experienced a relapse after a febrile attack-free period of more than 6 months. The median duration of the attackfree periods leading up to the relapse was 20 months [21].

Other studies, with a shorter follow-up, reported a spontaneous resolution in only $20-32 \%$ of the patients $[12,24,25]$.

Berkun et al. described a cohort of 124 PFAPA patients, of which 65 showed a single $M E F V$ mutation. PFAPA attacks in $M E F V$ carriers were shorter, compared with patients without mutations, and the frequency of their attacks and oral aphthae were also lower. This may suggest that mutations in causative genes of other monogenic periodic fevers may modify the disease course [37].

As shown in different studies, PFAPA may have its onset in adulthood as well $[11,16,38]$. To date, no long-term outcome data are available for adult patients diagnosed with PFAPA syndrome, so it is not known whether adults with PFAPA syndrome may spontaneously undergo clinical remission. Based on a review of the recent literature, tonsillectomy does not seem to be a valid option in these patients [39]. There are reports describing adult PFAPA patients with a history of tonsillectomy during childhood due to recurrent febrile tonsillo-pharyngitis, with subsequent disease free period of several years. These findings may suggest that tonsillectomy is efficacious in inducing a temporary remission but that the effect may be transient [40].

\section{Conclusions}

PFAPA syndrome is a relatively common condition in childhood, but it can also persist into adulthood. The disease usually has a benign and self-limiting course. Treatment with single doses of glucocorticoids is effective in controlling the fever episodes. Colchicine may be an interesting option for patients with frequent episodes. Tonsillectomy should be reserved for selected patients refractory to medical treatment and children with longlasting disease affecting the quality of life.

\section{Abbreviations}

FMF, familial mediterranean fever; HFP, hereditary periodic fever; MKD, mevalonate kinase deficiency; PFAPA, periodic fever, aphthous stomatitis, cervical adenitis

\section{Acknowledgements}

Not applicable.

Funding

None of the authors have any source of funding to declare in relation to this manuscript.

\section{Availability of data and materials}

Not applicable. This is a review paper, our findings reflects the data reported in the cited literature (see references list).

\section{Authors' contributions}

FV, KT and MH collaborated to draft the manuscript. All authors read and approved the final manuscript.

\section{Competing interests}

None of the authors have any financial or any non-financial competing interests (political, personal, religious, ideological, academic, intellectual, commercial or any other) to declare in relation to this manuscript.

\section{Consent for publication}

Not applicable.

Ethics approval and consent to participate

Not applicable.

\section{Author details}

${ }^{1}$ Pediatric Department of Southern Switzerland, Ospedale Regionale di Bellinzona e Valli, Bellinzona 6500, Switzerland. ${ }^{2}$ Unité Romande d'Immuno-rhumatologie Pédiatrique (URIRP), Département

Femme-Mère-Enfant (DFME), CHUV, University of Lausanne, Rue du Bugnon 46, Lausanne 1011, Switzerland. ${ }^{3}$ Unité Romande d'Immuno-rhumatologie

Pédiatrique (URIRP), Département Médico - Chirurgical de Pédiatrie (DFME),

CHUV, University of Lausanne, Rue du Bugnon 46, Lausanne 1011,

Switzerland.

Received: 8 April 2016 Accepted: 21 June 2016

Published online: 27 June 2016

\section{References}

1. Marshall GS, Edwards KM, Butler J, Lawton AR. Syndrome of periodic fever, pharyngitis, and aphthous stomatitis. J Pediatr. 1987;110(1):43-6. 
2. Thomas KT, Feder Jr HM, Lawton AR, Edwards KM. Periodic fever syndrome in children. J Pediatr. 1999;135(1):15-21.

3. Stojanov S, Hoffmann F, Kery A, Renner ED, Hartl D, Lohse P, Huss K Fraunberger P, Malley JD, Zellerer S, Albert MH, Belohradsky BH. Cytokine profile in PFAPA syndrome suggests continuous inflammation and reduced anti-inflammatory response. Eur Cytokine Netw. 2006;17(2):90-7.

4. Long S. "Syndrome of Periodic Fever, Aphthous stomatitis, Pharyngitis, and Adenitis (PFAPA) what it isn't. What is it? J Pediatr. 1999;135(1):1-5.

5. Stojanov S, Lapidusa S, Chitkara P, Feder H, Salazar JC, Fleisher TA, Brown MR, Edwards KM, Ward MM, Colbert RA, Sun H-W, Wood GM, Barham BK, Jones A, Aksentijevich I, Goldbach-Mansky R, Athreya B, Barron KS, Kastner DL. Periodic fever, aphthous stomatitis, pharyngitis, and adenitis (PFAPA) is a disorder of innate immunity and Th1 activation responsive to IL-1 blockade. Proc Natl Acad Sci U S A. 2011;108:7146-53.

6. Cochard M, Clet J, Le L, Pillet P, Onrubia X, Guéron T, Faouzi M, Hofer M. PFAPA syndrome is not a sporadic disease. Rheumatology (Oxford). 2010;49(10):1984-7.

7. Perko D, Debeljak M, Toplak N, Avčin T. Clinical features and genetic background of the periodic Fever syndrome with aphthous stomatitis, pharyngitis, and adenitis: a single center longitudinal study of 81 patients. Mediators Inflamm. 2015;2015:293417.

8. Dagan E, Gershoni-Baruch R, Khatib I, Mori A, Brik R. MEFV, TNF1rA, CARD15 and NLRP3 mutation analysis in PFAPA. Rheumatol Int. 2010;30(5):633-6.

9. Kolly L, Busso N, Von Scheven-Gete A, Bagnoud N, Moix I, Holzinger D, Simon G, Ives A, Guarda G, So A, Morris MA, Hofer M. Periodic fever, aphthous stomatitis, pharyngitis, cervical adenitis syndrome is linked to dysregulated monocyte IL-1ß production. J Allergy Clin Immunol. 2013;131(6):1635-43.

10. Gattorno M, Caorsi R, Meini A, Cattalini M, Federici S, Zulian F, Cortis E, Calcagno G, Tommasini A, Consolini R, Simonini G, Pelagatti MA, Baldi M, Ceccherini I, Plebani A, Frenkel J, Sormani MP, Martini A. Differentiating PFAPA syndrome from monogenic periodic fevers. Pediatrics. 2009;124(4):e721-8.

11. Padeh S, Stoffman N, Berkun Y. Periodic fever accompanied by aphthous stomatitis phayngitis and cervical adenitis syndrome (PFAPA syndrome) in adults. Isr Med Assoc J. 2008;10:358-60.

12. Feder HM, Salazar JC. A clinical review of 105 patients with PFAPA (a periodic fever syndrome). Acta Paediatr. 2010;99(2):178-84.

13. ter Haar N, Lachmann H, Ozen S, Woo P, Uziel Y, Modesto C, Kone-Paut I, Cantarini L, Insalaco a, Neven B, Hofer M, Rigante D, Al-Mayouf S, Touitou I, Gallizzi R, Papadopoulou-Alataki E, Martino S, Kuemmerle-Deschner J, Obici L, lagaru N, Simon a, Nielsen S, Martini a, Ruperto N, Gattorno M, Frenkel J. Treatment of autoinflammatory diseases: results from the Eurofever Registry and a literature review. Ann Rheum Dis. 2013;72(5):678-85.

14. Vigo G, Zulian F. Periodic fevers with aphthous stomatitis, pharyngitis, and adenitis (PFAPA). Autoimmun Rev. 2012;12(1):52-5.

15. Peridis S, Pilgrim G, Koudoumnakis E, Athanasopoulos I, Houlakis M, Parpounas K. PFAPA syndrome in children: A meta-analysis on surgical versus medical treatment. Int J Pediatr Otorhinolaryngol. 2010;74(11):1203-8.

16. Hofer M, Pillet P, Cochard M-M, Berg S, Krol P, Kone-Paut I, Rigante D, Hentgen V, Anton J, Brik R, Neven B, Touitou I, Kaiser D, Duquesne A, Wouters C, Gattorno M. International periodic fever, aphthous stomatitis, pharyngitis, cervical adenitis syndrome cohort: description of distinct phenotypes in 301 patients. Rheumatology (Oxford). 2014;53(6):1125-9.

17. Wurster VM, Carlucci JG, Feder HM, Edwards KM. Long-term follow-up of children with periodic fever, aphthous stomatitis, pharyngitis, and cervical adenitis syndrome. J Pediatr. 2011;159(6):958-64.

18. Tasher D, Somekh E, Dalal I. PFAPA syndrome: new clinical aspects disclosed. Arch Dis Child. 2006;91(12):981-4.

19. Yazgan H, Gultekin E, Yazicilar O, Sagun OF, Uzun L. Comparison of conventional and low dose steroid in the treatment of PFAPA syndrome: preliminary study. Int J Pediatr Otorhinolaryngol. 2012;76(11):1588-90.

20. Licameli G, Jeffrey J, Luz J, Jones D, Kenna M. Effect of adenotonsillectomy in PFAPA syndrome. Arch Otolaryngol Head Neck Surg. 2008;134(2):136-40.

21. Forsvoll J, Kristoffersen EK, Oymar K. Incidence, clinical characteristics and outcome in Norwegian children with periodic fever, aphthous stomatitis, pharyngitis and cervical adenitis syndrome; a population-based study. Acta Paediatr. 2013;102(2):187-92.

22. Leung YY, Yao Hui LL, Kraus VB. Colchicine-Update on mechanisms of action and therapeutic uses. Semin Arthritis Rheum. 2015:45(3):341-50.

23. Aviel YB, Tatour S, Gershoni Baruch R, Brik R. Colchicine as a therapeutic option in periodic fever, aphtous stomatitis, pharyngitis, cervical adenitis (PFAPA) syndrome. Syndrome. Semin Arthritis Rheum. 2016;45:471-4.
24. Padeh S, Brezniak N, Zemer D, Pras E, Livneh a, Langevitz P, Migdal a, Pras M, Passwell JH. Periodic fever, aphthous stomatitis, pharyngitis, and adenopathy syndrome: clinical characteristics and outcome. J Pediatr. 1999;135(1):98-101.

25. Tasher D, Stein M, Dalal I, Somekh E. Colchicine prophylaxis for frequent periodic fever, aphthous stomatitis, pharyngitis and adenitis episodes. Acta Paediatr. 2008;97:1090-2.

26. Dusser P, Hengten V, Neven B, Koné-Paut I. "Is colchicine an effective treatment in Periodic Fever, Aphthous stomatitis, Pharyngitis and Cervical adenitis (PFAPA) syndrome?" Joint Bone Spine. 2016; 83(4):406-11.

27. Feder HM. Cimetidine treatment for periodic fever associated with aphthous stomatitis, pharyngitis and cervical adenitis. Pediatr Infect Dis. 1992;11(4):318-21.

28. Frediana B, Cantarini L, Vitale A, Galeazzi M. A case of resistant adult-onset Periodic Fever, Aphthous stomatitis, Pharyngitis and Cervical adenitis (PFAPA) syndrome responsive to anakinra". Clin Exp Rheumatol. 2012;30(4):593.

29. Mangin M, Sinha R, Fincher K. "Inflammation and vitamin D: the infection connection" Inflamm Res. 2014; col 63, no 10, pp 803-819.

30. Mahamid M, Agbaria K, Mahamid A, Nseir W. Vitamin D linked to PFAPA syndrome. Int J Pediatr Otorhinolaryngol. 2013;77:362-4.

31. Stagi S, Bertini F, Rigante D, Falcini F. Vitamin D levels and effects of vitamin $D$ replacement in children with periodic fever, aphthous stomatitis, pharyngitis, and cervical adenitis (PFAPA) syndrome. Int J Pediatr Otorhinolaryngol. 2014;78(6):964-8.

32. Abramson JS TJ, Givner LB. Possible role of tonsillectomy and adenoidectomy in children with recurrent fever and tonsillopharyngitis. Pediatr Infect Dis. 1989;8(2):119-20.

33. Renko M, Salo E, Putto-Laurila A, Saxen H, Mattila PS, Luotonen J, Ruuskanen O, Uhari M. A Randomized, Controlled Trial of Tonsillectomy in Periodic Fever, Aphthous Stomatitis, Pharyngitis, and Adenitis Syndrome. J Pediatr. 2007;151(3):289-92.

34. Garavello W, Romagnoli M, Gaini RM. Effectiveness of adenotonsillectomy in PFAPA syndrome: a randomized study. J Pediatr. 2009;155(2):250-3.

35. Licameli G, Lawton M, Kenna M, Dedeoglu F. Long-term surgical outcomes of adenotonsillectomy for PFAPA syndrome. Arch Otolaryngol Head Neck Surg. 2012;138(10):902-6.

36. Burton MJ, Pollard AJ, Ramsden JD, Chong LYe, Venekamp RP. Tonsillectomy for periodic fever, aphthous stomatitis, pharyngitis and cervical adenitis syndrome (PFAPA). Cochrane Database Syst Rev. 2014:9:CD008669.

37. Berkun Y, Levy R, Hurwitz A, et al. The familial Mediterranean fever gene as a modifier of periodic fever, aphthous stomatitis, pharyngitis, and adenopathy syndrome. Semin Arthritis Rheum. 2011;40:467-72.

38. Cantarini L, Vitale A, Bartolomei B, Galeazzi M, Rigante D. Diagnosis of PFAPA syndrome applied to a cohort of 17 adults with unexplained recurrent fevers. Clin Exp Rheumatol. 2012;30(2):269-71.

39. Cattalini M, Soliani M, Rigante D, Lopalco G, lannone F, Galeazzi M, Cantarini L. Basic Characteristics of Adults with Periodic Fever, Aphthous Stomatitis, Pharyngitis, and Adenopathy Syndrome in Comparison with the Typical Pediatric Expression of Disease. Mediators Inflamm. 2015;2015:1-11.

40. Colotto M, Maranghi M, Durante C, Rossetti M, Renzi A, Anatra MG. PFAPA syndrome in a young adult with a history of tonsillectomy. Intern Med. 2011;50(3):223-5.

\section{Submit your next manuscript to BioMed Central and we will help you at every step:}

- We accept pre-submission inquiries

- Our selector tool helps you to find the most relevant journal

- We provide round the clock customer support

- Convenient online submission

- Thorough peer review

- Inclusion in PubMed and all major indexing services

- Maximum visibility for your research

Submit your manuscript at www.biomedcentral.com/submit
Biomed Central 